\title{
GESTÃO DEMOCRÁTICA NAS ESCOLAS
}

\author{
GESTIÓN DEMOCRATICA EN LAS ESCUELAS
}

DEMOCRATIC MANAGEMENT IN SCHOOLS

\author{
Vagner RAMOS SANTANA ${ }^{1}$
}

RESUMO: A gestão democrática pode ser considerada como o meio pelo qual todos os segmentos que compõem o processo educativo participam da definição dos rumos que a escola pretende trilhar. Gestão democrática traz, em si, a necessidade de uma postura democrática. Esta postura revela uma forma de encarar a educação e o ensino, na qual o Poder Público, o coletivo escolar e a comunidade local, juntos, estarão sintonizados para garantir a qualidade do processo. Importante ressaltar que a escola, deve assumir uma postura de qualidade social, que atenta ao desenvolvimento do ser social em todas as suas dimensões: no econômico, inserção no mundo do trabalho; no cultural, apropriação, desenvolvimento e sistematização da cultura popular e cultura universal; no político, emancipação do cidadão.

PALAVRAS-CHAVE: Gestão. Democrática. Escolas. Qualidade. Comunidade.

RESUMEN: La gestión democrática puede ser considerada como medio por el cual todos los segmentos que componen el proceso educativo participan de la definición de los rumbos que la escuela pretende recorrer. La gestión democrática trae, en sí, la necesidad de una postura democrática. Y esta postura revela una forma de encarar la educación y la enseñanza, donde el Poder Público, el colectivo escolar y la comunidad local, juntos, estarán sintonizados para garantizar la calidad del proceso. Es importante resaltar que la escuela, debe asumir una postura de calidad social, que atenta al desarrollo del ser social en todas sus dimensiones: en el económico, inserción en el mundo del trabajo; en el cultural, apropiación, desarrollo y sistematización de la cultura popular y cultura universal; en el político, emancipación del ciudadano.

PALABRAS CLAVE: Gestión. Democrático. Escuelas. Calidad. Comunidad.

ABSTRACT: Democratic management can be considered as a means by which all the segments that make up the educational process participate in defining the directions that the school intends to follow. Democratic management brings with it the need for a democratic stance. And this posture reveals a way of looking at education and teaching, where the Public Power, the school community and the local community together will be attuned to guarantee the quality of the process. It is important to emphasize that the school must assume a posture of social quality, which attentive to the development of the social being in all its dimensions: in the economic, insertion in the world of work; in

${ }^{1}$ Secretaria de Estado de Educação - (SEDUC), Nova Olímpia - MT - Brasil. Técnico Administrativo Educacional, Escola Francisca de Souza Alencar. E-mail: vagner_maximo@hotmail.com 
the cultural, appropriation, development and systematization of popular culture and universal culture; in the political, emancipation of the citizen.

KEYWORDS: Management. Democracy. Schools. Quality. Community.

\section{Introdução}

O novo paradigma da administração escolar traz, junto com a autonomia, a ideia e a recomendação de gestão democrática, com responsabilidades compartilhadas pelas comunidades interna e externa da escola.

Assim, a gestão democrática é um objetivo e um percurso. É um objetivo porque se trata de uma meta a ser sempre aprimorada e é um percurso, porque se revela como um processo que, a cada dia, se avalia e se reorganiza.

O papel da escola deve estar de acordo com os interesses da sociedade atual, ou seja, a escola precisa assumir as características de uma instituição que atenda às exigências geradas por esses fatores. Sendo assim, a gestão da escola precisa se empenhar para reestruturar a escola, pois a aprendizagem agora ocupa toda a vida das pessoas, além da escola, adquirem-se conhecimentos em diversos espaços, no familiar, no social e no virtual.

Desse modo, este trabalho teve como objetivo discutir a atuação da gestão escolar na busca pela mudança organizacional da escola para que a mesma proporcione um ensino de alto nível aos seus alunos.

A metodologia utilizada para a realização deste artigo foi a pesquisa exploratória, através de levantamento bibliográfico sobre o tema em livros, periódicos e sites da Internet.

Assim, o referencial teórico foi organizado a partir de análises de conteúdos relevantes para o estudo. O tratamento dos dados da pesquisa bibliográfica foi avaliado à luz dos teóricos que trabalham os conceitos utilizados.

\section{Gestão democrática nas escolas}

A gestão democrática pode ser considerada como meio pelo qual todos os segmentos que compõem o processo educativo participam da definição dos rumos que a escola deve imprimir à educação de maneira a efetivar essas decisões, num processo contínuo de avaliação de suas ações. 
A Constituição Federal estabelece no artigo 206 os princípios sobre os quais o ensino deve ser ministrado. Dentre eles, destaca-se a gestão democrática do ensino público, na forma da lei.

Cabe, no entanto, aos sistemas de ensino, definirem as normas da gestão democrática do ensino público na educação básica, de acordo com as suas peculiaridades e conforme os seguintes princípios:

a) participação dos profissionais da educação na elaboração do projeto pedagógico da escola;

b) participação das comunidades escolar e local em conselhos escolares ou equivalentes. (LDB - Art. 14)

Como condição para o estabelecimento da gestão democrática é preciso que os sistemas de ensino assegurem às unidades escolares públicas de educação básica que os integram, progressivos graus de autonomia pedagógica, administrativa e financeira, observadas as normas gerais de direito financeiro público. (LDB - Art. 15)

A democratização da educação indica a necessidade que o processo educativo tem de ser um espaço para o exercício da democracia. E para que isso aconteça, que seja concebida uma nova forma de conceber a gestão da educação: a gestão democrática.

Como elementos constitutivos dessa forma de gestão podem ser apontados: participação, autonomia, transparência e pluralidade (ARAÚJO, 2000). E como instrumentos de sua ação, surgem as instâncias diretas e indiretas de deliberação, tais como conselhos e similares, que propiciam espaços de participação e de criação da identidade do sistema de ensino e da escola. Assim, a gestão democrática da educação "trabalha com atores sociais e suas relações com o ambiente, como sujeitos da construção da história humana, gerando participação, co-responsabilidade e compromisso" (BORDIGNON; GRACINDO, 2001, p. 12).

Democratização da educação, nesse sentido, vai além das ações voltadas para a ampliação do atendimento escolar. Configura-se como uma postura que, assumida pelos dirigentes educacionais e pelos diversos sujeitos que participam do processo educativo, inaugura o sentido democrático da prática social da educação.

\section{Gestão democrática reflexo da postura escolar}

O princípio da gestão democrática está inscrito na Constituição Federal e na LDB, sendo assim, ele deve ser desenvolvido em todos os sistemas de ensino e escolas 
públicas do país. Ocorre, contudo, que como não houve a normatização necessária dessa forma de gestão nos sistemas de ensino, ela vem sendo desenvolvida de diversas formas e a partir de diferentes denominações: gestão participativa, gestão compartilhada, cogestão, etc. E é certo que sob cada uma dessas denominações, comportamentos, atitudes e concepções diversas são colocados em prática.

O termo aqui adotado é a gestão democrática por entendermos que este termo coloca em prática o espírito da Lei.

Assim, a gestão democrática é um objetivo e um percurso. É um objetivo porque trata-se de uma meta a ser sempre aprimorada e é um percurso, porque se revela como um processo que, a cada dia, se avalia e se reorganiza.

Parece óbvio lembrar que uma gestão democrática traz, em si, a necessidade de uma postura democrática. E esta postura revela uma forma de encarar a educação e o ensino, na qual o Poder Público, o coletivo escolar e a comunidade local, juntos, estarão sintonizados para garantir a qualidade do processo educativo.

\section{Partes da gestão democrática}

A gestão democrática na escola torna-se um processo de construção da cidadania emancipada. Para tanto, e segundo Araújo (2000), são quatro os elementos indispensáveis a uma gestão democrática: participação, pluralismo, autonomia e transparência.

A realidade mostra uma série de formas e significados dados ao sentido de participação na escola. Alguns exemplos identificam participação como simples processo de colaboração, de adesão e de obediência às decisões da direção da escola. Nesses casos, as decisões são tomadas previamente e os objetivos da participação também são delimitados antes dela ocorrer, segundo Bordignon e Gracindo (2000).

Perdem-se, dessa forma, duas condições básicas para uma efetiva participação:

1) O sentido público de um projeto que pertence a todos.

2) O sentido coletivo da sua construção, que oferece iguais oportunidades a todos, nas suas definições. Assim, a participação adquire caráter democrático e torna-se propiciadora da ação comprometida dos sujeitos sociais. Dessa forma, a participação requer a posição de governantes, não de meros coadjuvantes, ou seja, requer espaços de poder. Portanto, ela só é possível em clima democrático. 
A participação é, portanto, condição básica para a gestão democrática: uma não é possível sem a outra. Uma das questões a serem enfrentadas na gestão democrática é o respeito e a abertura de espaço para o "pensar diferente”. É o pluralismo que se consolida como postura de "reconhecimento da existência de diferenças de identidade e de interesses que convivem no interior da escola e que sustentam, através do debate e do conflito de idéias, o próprio processo democrático" (ARAÚJO, 2000 p. 134). Nota-se, que a maior resistência encontrada a essa postura pluralista está, em grande parte, na consequente distribuição de poder que ela enseja. Nesse sentido, ratificando a idéia da necessidade de desconcentração do poder, Bobbio (1994 p.15) esclarece que "uma sociedade é tanto melhor governada, quanto mais repartido for o poder e mais numerosos forem os centros de poder que controlam os órgãos do poder central".

Vale considerar que "o conceito de autonomia está ligado à idéia de autogoverno, isto é, à faculdade que os indivíduos têm de se regerem por regras próprias" (BARROSO, 1998). Escola autônoma é, portanto, aquela que constrói o seu PP de forma coletiva, como estratégia fundamental para sua emancipação e para a transformação social. Assim, a autonomia precisa ser conquistada a partir da democratização interna e externa da escola, politizando o espaço escolar e propiciando o desenvolvimento de duas facetas importantes da autonomia escolar: a autonomia da escola e a autonomia dos sujeitos sociais (ARAÚJO, 2000).

Como outro elemento fundamental da gestão democrática, a transparência está intrinsecamente ligada à ideia de escola como espaço público. Face ao predomínio da lógica econômica em todos os setores sociais, em especial na educação, garantir a visibilidade da escola frente à sociedade, torna-se uma questão ética. Quase como um amálgama dos elementos constitutivos da gestão democrática, a transparência afirma a dimensão política da escola. Sua existência pressupõe a construção de um espaço público vigoroso e aberto às diversidades de opiniões e concepções de mundo, contemplando a participação de todos que estão envolvidos com a escola (ARAÚJO, 2000, p. 155).

Descrevendo os elementos constitutivos da gestão democrática, fica evidente um conceito transversal a todos eles: o de democratização da educação (GRACINDO, 2003). E ele se torna o fio condutor e a base de reflexão/ação da gestão democrática, isto é, participação, pluralismo, autonomia e transparência não se instauram sem a cultura democrática. Agregado à postura de democratização da educação, outro conceito permeia todas as reflexões desenvolvidas: a idéia de escola como espaço público. Isto é, 
sem o sentido público, a escola não viabilizará participação, pluralismo, autonomia e transparência.

Pode-se afirmar que em última instância, a cultura democrática e o sentido público da prática social da educação são alicerces da gestão democrática.

Ocorre que todos esses elementos e alicerces da gestão democrática necessitam de uma base concreta para sua viabilização: os espaços de encontro, discussão e trocas. Dentre esses múltiplos espaços destacam-se: os conselhos deliberativos e consultivos, os grêmios estudantis, as reuniões, as assembléias e as associações. A partir desses espaços de prática democrática são deliberados e construídos os caminhos que a escola deve percorrer. E o retrato dessa caminhada será revelado no Projeto PolíticoPedagógico da escola.

\section{Gestão democrática: estratégias e instrumentos}

O Brasil possui profundas desigualdades econômicas, culturais e políticas que geraram segregação de grupos sociais e a negação da cidadania a um enorme contingente de brasileiros. Essa realidade, no entanto, não pode ser aceita passivamente por seus cidadãos e requer, do Estado, o estabelecimento de políticas públicas voltadas para a redução dessas enormes diferenças e para a inclusão social.

Os mecanismos democráticos de atuação da sociedade civil requerem, de um lado, a escolha consciente dos seus representantes nas mais diversas instâncias de poder e, de outro, a participação direta e ativa do cidadão em muitas arenas de decisão política.

A gestão democrática é uma prática prevista na Constituição Federal, na Lei de Diretrizes e Bases da Educação Nacional (LDB) e no Plano Nacional de Educação (PNE). É uma forma de exercitar a democracia participativa, podendo contribuir para a própria democratização da sociedade.

Assim, dentre os muitos espaços possíveis de participação da sociedade, a escola torna-se instrumento importante para o desenvolvimento da democracia participativa. Surge, então, a gestão democrática da educação, como uma construção coletiva da sociedade, que favorece o exercício da cidadania.

O Conselho Escolar, entre outros mecanismos, tem papel decisivo na gestão democrática da escola, se for utilizado como instrumento comprometido com a construção de uma escola cidadã. Assim, constitui-se como um órgão colegiado que 
representa a comunidade escolar e local, atuando em sintonia com a administração da escola e definindo caminhos para tomar decisões administrativas, financeiras e políticopedagógicas condizentes com as necessidades e potencialidades da escola.

Desta forma, a gestão deixa de ser prerrogativa de uma só pessoa e passa a ser um trabalho coletivo, em que os segmentos escolares e a comunidade local se congregam para construírem uma educação de qualidade e socialmente relevante. Com isso, divide-se o poder e as conseqüentes responsabilidades.

A composição, funções, responsabilidades e funcionamento dos Conselhos Escolares devem ser estabelecidos pela própria escola, a partir de sua realidade concreta e garantindo a natureza essencialmente político-educativa do Conselho Escolar, que se expressa no comprometimento que desenvolve durante todo o processo educacional, com uma focalização privilegiada na aprendizagem. Sua atuação, desta forma, se volta para: o planejamento, a aplicação e a avaliação das ações da escola.

O Conselho Escolar deve estar atento a alguns aspectos extremamente relevantes desse processo, compreendendo que:

a) O projeto de educação que a escola vai desenvolver, dando sentido às suas ações, deve ser discutido, deliberado e seguido por todos.

b) $\mathrm{O}$ sentido de pluralidade nas relações sociais da escola, com respeito às diferenças existentes entre os sujeitos sociais, deve ser a marca do processo educativo.

c) O sentido de qualidade na educação não pode ser uma simples transposição deste conceito do mundo empresarial para a escola, isto é, na educação, esse sentido necessita estar referenciado no social e não no mercado.

d) A escola como um todo é responsável pelo sucesso ou pelo fracasso do estudante, partilhando a responsabilidade pelo desenvolvimento da prática educativa.

e) A aprendizagem é decorrente da construção coletiva do conhecimento e não se basta à transmissão de informações.

f) $\mathrm{Na}$ avaliação da aprendizagem do estudante, cabe verificar mais do que o produto da aprendizagem, cabe analisar todo o processo no qual ele se desenvolveu. Assim, devem ser considerados: o contexto social; a gestão democrática; a ação docente; e as condições físicas, materiais e pedagógicas da escola.

g) A escola, como equipamento social público, deve ser transparente nas suas ações.

h) Os espaços de participação nas decisões da escola devem ser ampliados cada vez mais, seja no processo de escolha de dirigentes, seja nas deliberações acerca das questões financeiras, pedagógicas e administrativas. 
i) A solidariedade e a inclusão social são princípios fundamentais da escola.

Com esses cuidados e tendo a dimensão da importância da gestão democrática da educação, na democratização mais ampla da sociedade, o Conselho Escolar dá uma contribuição altamente relevante para que a educação desenvolvida pela escola possa ser instrumento para a emancipação dos sujeitos sociais e para o cumprimento de seu papel social.

\section{Considerações finais}

O Conselho Escolar, como órgão consultivo, deliberativo e de mobilização mais importante do processo de gestão democrática, não deve configurar-se como instrumento de controle externo, mas como um parceiro de todas as atividades que se desenvolvem no interior da escola. E, nessa linha de raciocínio, a função principal do Conselho Escolar está ligada à essência do trabalho escolar, isto é, está voltada para o desenvolvimento da prática educativa.

Nessa prática, o processo de ensino-aprendizagem deve ser o foco principal. A ação do Conselho Escolar torna-se político-pedagógica, pois se expressa numa ação sistemática e planejada, com o intuito de interferir sobre a realidade, transformando-a.

Importante destacar que o sentido dado ao termo qualidade tem tomado formas e conteúdos diversos, na medida em que ele não é auto-explicativo.

Com isso, pode-se perceber que, no campo educacional, esse termo tem-se apresentado em duas vertentes diferentes e antagônicas: uma, com sentido de qualidade mercantil, baseado na lógica econômica e empresarial, que se referencia no mercado e outra, com sentido de qualidade socialmente referenciada, a qual possui uma lógica que tenta compreender a relevância social da construção dos conhecimentos e de posturas na escola.

Diferenciar esses dois tipos de concepção do termo qualidade parece ser fundamental para a prática social da educação, pois para cada um desses sentidos são estabelecidas concepções diferentes de educação e, conseqüentemente, formas diferenciadas de gestão.

Essa lógica implantada no seio do processo educacional contribui para a adesão de muitos dirigentes educacionais à gerência para a qualidade total que, tal como Paiva 
(1994) alertou, pauta-se na produtividade e na competitividade, indicando a gestão empresarial como fórmula a ser aplicada à gestão da educação; optando pelo pragmatismo como aspecto fundamental dos objetivos educacionais; e indica a supremacia da avaliação de produtos.

Nessa ótica, a escola passa a assumir-se como uma empresa que, por sua nova natureza, não identifica a educação como direito, nem age para propiciar a inclusão de todos em sua "linha de montagem", uma vez que naturaliza a exclusão daqueles que não se adaptam ao "processo produtivo" que desenvolve.

O sentido de qualidade referenciada no social, por outro lado, possui outra lógica que o sustenta. Sua base é decorrente do desenvolvimento de relações sociais contextualizadas e sua gestão, diferentemente da anterior, contribui para o fortalecimento da escola pública, construindo uma relação efetiva entre democratização e qualidade.

A qualidade na educação, com esse significado, busca construir a emancipação dos sujeitos sociais. Para tanto, desenvolve conhecimentos, habilidades e atitudes que irão encaminhar a forma mediante a qual o indivíduo vai se relacionar com a sociedade, com a natureza e consigo mesmo, a partir da concepção de mundo, sociedade e educação que possui.

Assim, a qualidade referenciada no social, e não no mercado, contribui com a formação dos sujeitos como cidadãos no mundo. Nesse sentido, a qualidade social está intimamente ligada à transformação da realidade e não à sua manutenção.

Importante ressaltar que a escola, ao assumir a qualidade social, está atenta ao desenvolvimento do ser social em todas as suas dimensões: no econômico (inserção no mundo do trabalho); no cultural (apropriação, desenvolvimento e sistematização da cultura popular e cultura universal); no político (emancipação do cidadão).

Se a finalidade última da educação é a formação de cidadãos, então, a qualidade da educação precisa estar voltada para esse fim e necessita sustentar-se em um tipo de gestão que propicie o exercício da cidadania, promovendo a participação de todos os segmentos que compõem a escola, além da comunidade local externa, ou seja, deve se sustentar na gestão democrática.

\section{REFERÊNCIAS}

ARAUJO, Adilson César. Gestão democrática da educação: a posição dos docentes. 
2000. 220 f. Dissertação (Mestrado em Educação) - Faculdade de Educação, Universidade de

Brasília, Brasília.

BARROSO, João. O reforço da autonomia das escolas e a flexibilização da gestão escolar em Portugal. In: FERREIRA, Naura S.Carapeto (org.). Gestão Democrática da Educação: atuais tendências, novos desafios. São Paulo: Cortez, 1998.

BOBBIO, Norberto. $O$ futuro da democracia: uma defesa das regras do jogo. Rio de Janeiro: Paz e Terra, 2000.

BORDIGNON, Genuíno; GRACINDO, Regina Vinhaes. Gestão da Educação: o município e a escola. In: FERREIRA, Naura; AGUIAR, Márcia (orgs.). Gestão da Educação: impasses, perspectivas e compromissos. São Paulo: Cortez, 2000.

BRASIL. Lei de Diretrizes e Bases da Educação, Lei n⿳0 9.394/96, de 20 de dezembro de 1996.

GENTILLI, P.; SILVA, T. T. (orgs.). Neoliberalismo, qualidade total e educação. Rio de Janeiro: Vozes, 1994.

RODRIGUES, Neidson. Por uma nova escola: o transitório e o permanente na educação. São Paulo: Cortez-Autores Associados, 1986.

\section{Como referenciar este artigo}

RAMOS SANTANA, Vagner. Gestão democrática nas escolas. Revista on line de Política e Gestão Educacional, Araraquara, v. 22, n. 2, p. 524-533, maio/ago., 2018. ISSN: 1519-9029. DOI: 10.22633/rpge.v22.n2.maio/ago.2018.11281

Submetido em: 09/04/2018

Revisões Requeridas: 26/04/2018

Aprovado em: 16/05/2018 